\title{
Narciclasine - an Amaryllidaceae Alkaloid with Potent Antitumor and Anti-Inflammatory Properties
}

Author

Affiliation
Robert Fürst

Institute of Pharmaceutical Biology, Biocenter, Goethe University, Frankfurt/Main, Germany
Key words

- Amaryllidaceae

- narciclasine

- alkaloids

- inflammation

- cancer

\section{Abstract}

$\nabla$

The isocarbostyril alkaloid narciclasine, also known as lycoricidinol, was discovered in Narcissus species (Amaryllidaceae) in 1967. A few years later, the $60 \mathrm{~S}$ subunit of ribosomes, and thus protein biosynthesis, were shown to be directly targeted by narciclasine. Due to its selective and highly potent cytotoxic action on cancer cells, narciclasine was intensively investigated as an antitumor compound both in vitro and in vivo. However, narciclasine did not show a strong pharmacological activity in animal tumor models. During the last decade, new fascinating actions, mechanisms, and targets of narciclasine have emerged. This review intends to present a brief but comprehensive overview of these novel insights. Beneficial therapeutical actions have been reported particularly in brain tumor models. The translation elongation factor eEF1A, which does not only participate in protein biosynthesis but also in the regulation of the actin cytoskeleton, was discovered as new direct target. Moreover, narciclasine was found to trigger actin stress fiber formation via the activation of the small GTPase RhoA. Progress has also been made regarding the pharmacokinetic characterization of the alkaloid. The synthesis of a great number of narciclasine derivatives led to a substantial understanding of its pharmacophore and of the structure-activity relationships. However, an optimized compound did not result from these efforts. Most importantly, a new field of indication has emerged: Narciclasine was proven to exert profound antiinflammatory actions in vivo. Taken together, there has been a strong advance in the preclinical knowledge about the alkaloid. Nevertheless, narciclasine has not been tested in human clinical trials up to now. received July 21,2016

revised August 5, 2016

accepted August 8, 2016

\section{Bibliography}

Dol http://dx.doi.org/ 10.1055/s-0042-115034

Published online August 19, 2016

Planta Med 2016; 82:

1389-1394 @ Georg Thieme

Verlag KG Stuttgart · New York . ISSN 0032-0943

\section{Correspondence}

Robert Fürst, PhD

Institute of Pharmaceutical

Biology

Biocenter

Goethe University

Max-von-Laue-Str. 9

60438 Frankfurt/Main

Germany

Phone: + 496979829655

Fax: + 496979876329655

fuerst@em.uni-frankfurt.de

\section{Amaryllidaceae Alkaloids}

\section{$\nabla$}

The natural compound narciclasine was named after the plant genus Narcissus (daffodil), which belongs to the Amaryllidaceae (amaryllis) family. The medical use of different Narcissus species dates back to ancient times. Famous physicians of this period, such as Hippocrates of Kos (4th century BC) or Pedanius Dioscorides (1st century $A D)$, recommended narcissus oil as a treatment against cancer, in particular uterine tumors [1]. This tradition was perpetuated during medieval times, e.g. in France by Henri de Mondeville (14th century AD) [1]. The pharmacologically most interesting secondary metabolites present in plants of the Amaryllidaceae family are alkaloids. Their scientific evaluation started in 1877 with the isolation of lycorine (OFig. 1) [2], the prototypical and most widely spread representative of the Amaryllidaceae alkaloids. Its chemical structure was published in 1956 [3]. The Amaryllidaceae family consists of 75 genera with about 1600 species [4], from which approximately 500 different alkaloids have been identified up to now. Based on the underlying skeleton, these compounds can be classified into at least nine different groups. Some authors even expanded this classification to 18 groups [5-7]. The most important prototypes of the nine classes are norbelladine, lycorine, homolycorine, haemanthamine, tazettine, montanine, galanthamine, crinine, and narciclasine ( $\odot$ Fig. 1) [7-10]. The Amaryllidaceae alkaloids have been found to exert a huge variety of pharmacological properties, such as antiproliferative, antitumor/cytotoxic, acetylcholinesterase inhibitory, analgesic, hypotensive, antibacterial, and antifungal activities [11]. The intensive research of the last decades, consisting of isolation, structure elucidation, analysis of structure-activity relationship, total synthesis, and pharmaco- 
logical characterization, has shed light on their tremendous potential. In fact, in 2000/2001, the Amaryllidaceae alkaloid galanthamine ( Fig. 1), which was discovered in Galanthus woronowii (Caucasian snowdrop), was approved for the treatment of mild to moderate forms of Alzheimer's disease in Europe and in the USA.

\section{The Discovery of Narciclasine}

$\nabla$

Narciclasine ( Fig. 1) was first isolated in 1967 from bulbs of several Narcissus species within a research program looking for antigrowth factors [12]. One year later, a chemical structure was proposed [13], but turned out to be incorrect. It was revised in $1970[14,15]$ and the stereochemistry was fully elucidated by X-ray analysis in 1972 [16]. Narciclasine bears the substructures of isoquinoline, phenanthridine, and isocarbostyril. Due to the amide structure, it is not a basic alkaloid. Interestingly, the Amaryllidaceae alkaloid lycoricidinol, which was first isolated in 1968 as plant-growth regulator from the bulbs of Lycoris radiata (red spider lily) [17], turned out to be identical to narciclasine [18]. Thus, narciclasine was discovered independently by two different groups at almost the same time. In the following years, the compound as well as congeners thereof (e.g. narciprimine, 7-deoxynarciclasine, trans-dihydronarciclasine, or 4- 0 - $\beta$-D-glucosylnarciclasine) were also found in a variety of other Amaryllidaceae genera (e.g. Haemanthus, Galanthus, Hymenocallis, or Leucojum) $[8,19-23]$. The amount of narciclasine in these plants was reported to vary from $1.5 \mathrm{mg} / \mathrm{kg}$ (fresh bulbs) to $200 \mathrm{mg} / \mathrm{kg}[8,19]$. An intriguing discovery was made in 2005: narciclasine was found in the Texas grasshopper Brachystola magna [24]. As this animal does not prefer species of the Amaryllidaceae family as food, undiscovered plant sources of narciclasine might still exist. Surprisingly, despite the intensive research on narciclasine, the first total synthesis was not developed until 1997 [25]. Up to now, six different total syntheses of narciclasine and one of the enantiomeric molecule have been published $[26,27]$. The number of steps necessary to build up the compound ranges between 11 and 22.

\section{The Biosynthesis of Narciclasine}

$\nabla$

Narciclasine originates from $\mathrm{O}$-methylnorbelladine, the central precursor of all Amaryllidaceae alkaloids. The biosynthesis of this precursor was intensively investigated in the late 1950s and early 1960s by tracer experiments with radiolabeled precursors and intermediates [28]: 0 -methylnorbelladine derives from the aromatic amino acids phenylalanine and tyrosine. Phenylalanine is transformed to protocatechuic aldehyde via trans-cinnamic acid, p-coumaric acid, and caffeic acid. Protocatechuic aldehyde reacts with tyramine, the decarboxylated form of tyrosine, yielding an imine (Schiff's base) that is reduced and methylated to 0 -methylnorbelladine. The subsequent biosynthetic route to narciclasine was studied in the early 1970s $[8,19,29-32]$ : It was suggested to start with the cyclization of 0 -methylnorbelladine by a para-para phenol coupling reaction ( Fig. 2 ). The resulting compound is eventually converted into narciclasine via the intermediate 11hydroxyvittatine and by an elimination of two carbon atoms (- Fig. 2). Although considerable progress has been made in the last years in the field of metabolic engineering for the production of plant isoquinoline alkaloids [33], the knowledge about the bio-

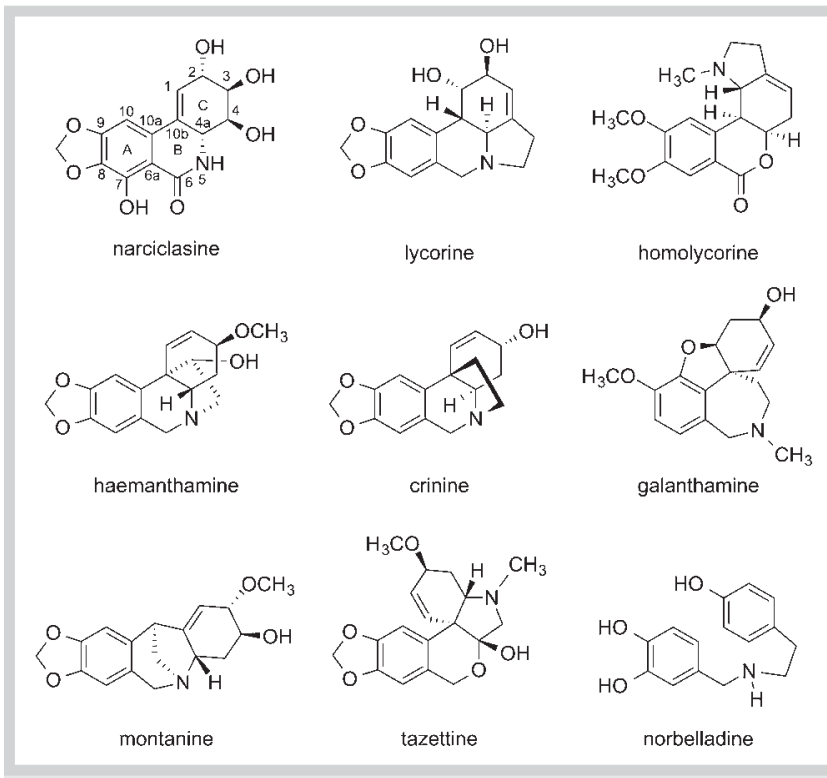

Fig. 1 Chemical structures of narciclasine and eight other prototypes of Amaryllidaceae alkaloids.

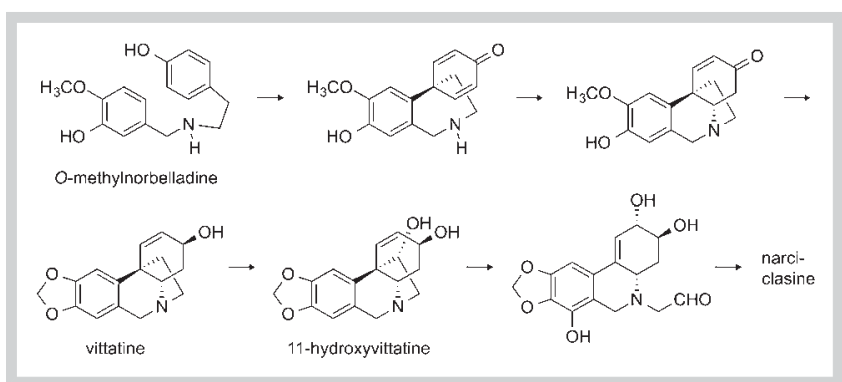

Fig. 2 Proposed biosynthetic route from $\mathrm{O}$-methylnorbelladine to narciclasine.

synthesis of narciclasine has not expanded significantly since the 1970s. Neither the involved enzymes nor their respective genes have been characterized. This knowledge, however, would be strongly needed for a rational biotechnological approach, in particular to solve the supply issue, by producing narciclasine in an efficient way in plants or in microorganisms, e.g. by heterologous expression.

\section{Preclinical Knowledge About Narciclasine \\ $\nabla$}

The subsequently presented knowledge about the pharmacological actions, the underlying mechanisms, and the target of narciclasine are graphically summarized in the $\bullet$ Fig. 3 .

\section{Anti-tumor activity}

Narciclasine inhibits cell growth by blocking protein biosynthesis. The initial publication describing the isolation of narciclasine also contains the first evaluation of its bioactivity: The compound showed a strong mitosis-blocking activity, since it effectively inhibited the growth of wheat grain radicles $(0.05-0.5 \mu \mathrm{g} / \mathrm{mL})$ as well as of murine sarcoma cells in vivo (oral and subcutaneous 
application) [12]. The first study proposing a mechanistic explanation of these actions was published in 1975: Carrasco et al. [34] reported that the alkaloid inhibits protein synthesis in rabbit reticulocytes as well as in a yeast-derived cell-free system by blocking peptide bond formation at the ribosome. These results were corroborated and largely expanded by further detailed studies published between 1975 and 1978 by the group of Vazquez [3539]: Narciclasine blocked protein synthesis with an $\mathrm{IC}_{50}$ of $70 \mathrm{nM}$ and inhibited HeLa (human cervix carcinoma) cell growth with a comparable $\mathrm{IC}_{50}$ of $100 \mathrm{nM}$. RNA synthesis was not affected, whereas DNA synthesis was slightly diminished, but only at much higher concentrations. The mechanistic basis of this effect has not been clarified, however, a direct interaction of narciclasine with the DNA (complex formation) was excluded [40]. The binding site of narciclasine was located in the 60S subunit of the ribosome and found to overlap with that of the known peptidyl transferase inhibitors anisomycin and trichodermin. Two decades later, narciclasine was utilized as a chemical probe to study the fine structure of the ribosomal peptidyl transferase center [41]. In 2014, X-ray crystallography was applied to decipher the exact binding mode of 16 different ribosome inhibitors, among them narciclasine, at the atomic level in yeast ribosomes [42]. This study confirmed that narciclasine inhibits the step of peptide bond formation during elongation by binding to the $60 \mathrm{~S}$ tRNA A-site.

Mechanisms beyond ribosome inhibition. In the early 1990s, the group of G. Pettit reported about the broad cytotoxic activities of narciclasine against a variety of cancer cells after the compound was tested in the NCI panel of 60 human tumor cell lines [43]. The mean $\mathrm{IC}_{50}$ of narciclasine in this screening was $15.5 \mathrm{nM}$. Interestingly, melanoma cell lines were the most sensitive tumor cells. Besides the in vitro screening approach, the $\mathrm{NCI}$ also performed a number of tests on tumor models in mice [44]. However, the overall efficacy of narciclasine was only modest and associated with a considerable toxicity. Surprisingly, the mechanisms underlying the narciclasine-induced death of cancer cells was not investigated until 2007: Dumont et al. [45] showed that narciclasine was cytotoxic to all investigated cancer cell lines ( $\mathrm{IC}_{50}$ : $30 \mathrm{nM})$, whereas much higher concentrations were need to interfere with the viability of fibroblasts $\left(\mathrm{IC}_{50}: 7.5 \mu \mathrm{M}\right.$ ). Ingrassia et al. [46] confirmed this selectivity towards cancer cells (mean $\mathrm{IC}_{50}$ : $38 \mathrm{nM}$ ) and reported that endothelial cells (HUVECs) are more sensitive than fibroblasts, since narciclasine inhibited the proliferation of endothelial cells with an $\mathrm{IC}_{50}$ of approx. $90 \mathrm{nM}$. This points towards a possible antiangiogenic action of the alkaloid. In fact, unpublished data from our own lab confirm this hypothesis.

Narciclasine used at the high concentration of $1 \mu \mathrm{M}$ was proven to cause apoptotic cancer cell death via activation of the Fas and death receptor 4 (DR4) death-inducing complex (DISC) and the subsequent recruitment of caspase-8 [45]. Interestingly, whether downstream effector caspases (e.g. caspase-3) are activated directly or via mitochondria depends on the cell type: In the prostate cancer cell line PC-3, narciclasine directly activated effector caspases via the Fas/DR4-triggered assembly of DISC and the activation of caspase-8. In the breast cancer cell line MCF-7, however, the activation of effector caspases depended on the processing of Bid, the release of cytochrome $\mathrm{c}$ from mitochondria and the subsequent formation of the apoptosome [45]. In human promyeloic HL-60 cells and in human oral cavity squamous carcinoma HSC-2 cells, also low concentrations of narciclasine (18 and $50 \mathrm{nM}$, re-

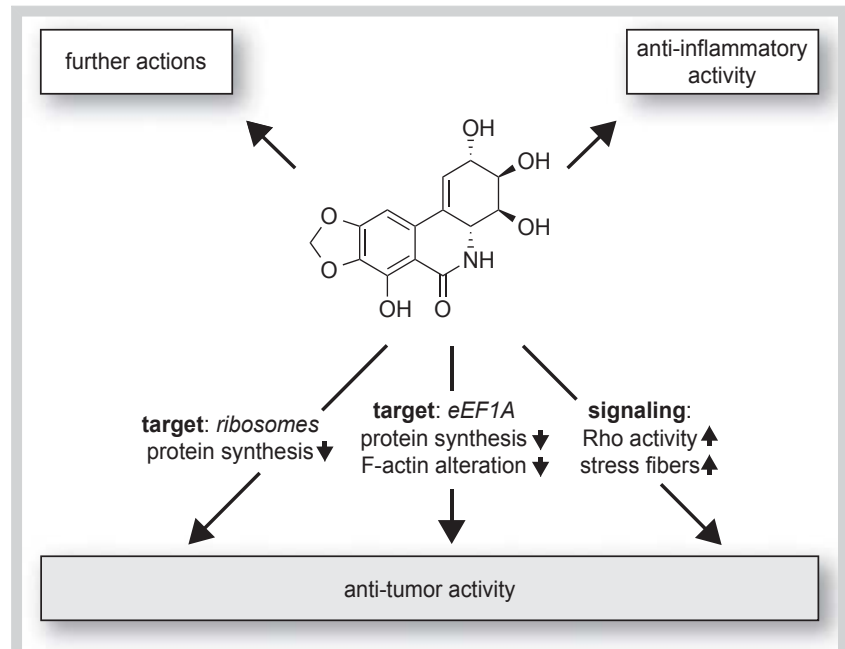

Fig. 3 The most important biological actions, targets and mechanisms of narciclasine.

spectively) have been proven to induce apoptosis (cell shrinkage, DNA fragmentation, caspase-3 activation) [47].

In contrast, narciclasine used at the concentration of $100 \mathrm{nM}$ was also found to impair tumor cell growth without inducing apoptosis: The alkaloid blocked the proliferation and migration of glioblastoma cells in vitro, but did not trigger apoptotic cell death [48]. The authors of the study did not claim the inhibition of translation as mechanistic basis of the antitumor effect, but provided evidence that narciclasine activates the small GTPase RhoA [48]. Of note, RhoA was not suggested or investigated as a direct target of narciclasine. The activation of RhoA eventually led to the formation of F-actin stress fibers via the Rho kinase/LIM kinase/ cofilin pathway. The increased generation of stress fibers was speculated to be the basis for the inhibition of cytokinesis and thus mitosis/proliferation, as well as for the decreased migratory capacity of glioblastoma cells. In the same study, the authors also tested narciclasine in vivo in a murine orthotopic model of human glioblastoma tumors. In contrast to the above mentioned disappointing in vivo results gathered by the NCI [44], narciclasine ( $1 \mathrm{mg} / \mathrm{kg}$, orally or via tail vein injections) was able to considerably act against the glioblastoma tumor and to significantly increase the survival of the glioblastoma-bearing mice [48].

Van Goietsenoven et al. [49] studied narciclasine in another hardto-treat brain tumor. They implanted human brain metastatic and apoptosis-resistant VM-48 melanoma cells into the brains of immunodeficient mice. Animals that were treated with narciclasine $(1 \mathrm{mg} / \mathrm{kg}$, orally) showed a significant therapeutic benefit that was even slightly stronger than that of the established chemotherapeutic agent temozolomide. The authors investigated the action of narciclasine on these melanoma cells in detail and discovered a new direct target of the alkaloid, the eukaryotic translation elongation factor eEF1A [49]. Binding of narciclasine to eEF1A was predicted by molecular docking analysis and proven in a cell-free system with recombinant human eEF1A as well as in a cellular assay using two melanoma cell lines. eEF1A is a very interesting protein: On the one hand, it delivers aminoacyltRNAs to the empty A-site of ribosomes, on the other hand, it binds to actin and participates in the organization of the actin cytoskeleton [50]. Thus, it regulates the morphology, cytokinesis, and migration of cells. Surprisingly, although migratory processes 
in cancer cells are inhibited by narciclasine [48], a collagen invasion assay revealed that the invasive capacity of human cervix carcinoma cells (HeLa) was not influenced by narciclasine at a concentration of $50 \mathrm{nM}$ [51]. This might be due to the fact that cancer cell invasion does not only consist of a migratory component. Another important factor is the interaction of the tumor cell with the extracellular matrix.

\section{Anti-inflammatory actions}

The first report on its anti-inflammatory properties was published in 1999: Mikami et al. [52] demonstrated that narciclasine effectively prevents paw swelling in a rat arthritis model. They also showed that narciclasine suppresses the production of TNF- $\alpha$ in LPS-activated murine macrophages. The authors ascribed this effect to the protein synthesis-blocking action of narciclasine [53]. In 2011, the alkaloid was reported to inhibit LPS-triggered NO production in a murine macrophage cell line (RAW264) as well as the generation of TNF- $\alpha$ in a human monocytic cell line (THP-1) [54]. One year later, Lubahn et al. [55] provided evidence that narcistatin, a water-soluble cyclic phosphate prodrug of narciclasine (see below), was able to reduce inflammation (by approx. $70 \%$ ) and joint destruction (by approx. 50\%) in rat adjuvant-induced arthritis after disease onset. Moreover, narcistatin also decreased the production of pro-inflammatory cytokines in different types of leukocytes. In 2015, our group characterized the anti-inflammatory effect of a narciclasine-containing extract of Haemanthus coccineus in two murine models of inflammation (dermal edema formation by arachidonic acid or croton oil and kidney injury caused by unilateral ureteral obstruction) [56]. The extract blocked the pro-inflammatory activation of leukocytes and endothelial cells. Interestingly, we could not detect any action on the activation cascade of the most prominent proinflammatory transcription factor $\mathrm{NF} k \mathrm{~B}$, but found a strong inhibition on the NFkB-dependent gene transcription in endothelial cell. We are currently performing further experiments in order to fully understand the anti-inflammatory potential and underlying mechanisms of the alkaloid.

\section{Further pharmacological activities}

In 1992, data on the antiviral actions of narciclasine were published. The compound was found to be active in vitro against three flaviviruses (Japanese encephalitis, yellow fever, and dengue fever), but not against the human immunodeficiency virus 1 (HIV-1) and the vaccinia virus. However, the activity was very weak and the concentrations needed were too close to those inducing cytotoxicity in uninfected cells [57].

More recently, in 2012, the influence of narciclasine on the circadian clock of cells was investigated. The alkaloid reversibly extended the circadian period. This effect was not caused by the inhibition of protein translation, but by an altered transcription of the core clock gene Bmal1 [58].

Interestingly, in 2015, Kim et al. [59] investigated the action of narciclasine in the context of the Alzheimer's disease. The alkaloid decreased the production of amyloid beta $(A \beta)$ by attenuating amyloid precursor levels in vitro. In a murine Alzheimer model, a narciclasine-containing extract from the plant Lycoris chejuensis reduced the levels of $A \beta$ and plaques, and showed beneficial effects on cognitive functions.

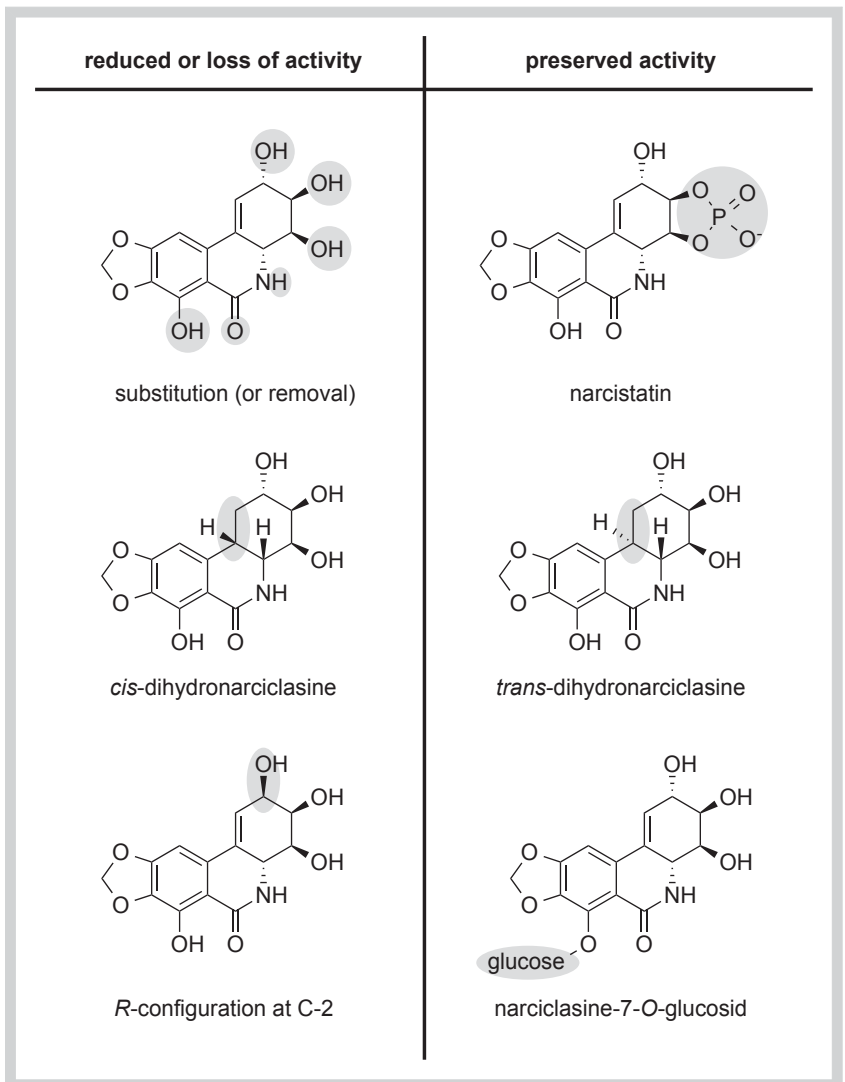

Fig. 4 Summary of the structural modifications of narciclasine and their impact on the biological activity.

\section{Narciclasine as a Lead Compound \\ $\nabla$}

By analyzing the action of several derivatives, first insights into the structure-activity relationship of narciclasine were already established in the 1970s. The tri-hydroxylated ring $C$ seems to be a critical part of the molecule ( Fig. 4): Hydrophobic substituents decreased the inhibitory activity on peptide bond formation and reduced the cytotoxicity against cancer cells [60,61]. A loss of each of the three hydroxyl groups also attenuated the biological activity [62-64]. Interestingly, after reduction of the double bond between C-1 and C-10b ( Fig. 4), the resulting cisdihydronarciclasine showed a weaker activity, whereas the trans-derivative was as active as narciclasine [51]. Pettit et al. [65] analyzed the biological activity of 7-deoxynarciclasine and 7-deoxy-trans-dihydronarciclasine ( Fig. 4). Both modifications diminished the cytotoxic activity against tumor cells. A huge number of narciclasine derivatives were synthesized by the group of R. Kiss [46]: Narciclasine was modified by the systematic addition of different substituents to each of the hydroxyl groups $(\mathrm{C}-2 / 3 / 4)$, to the phenolic $\mathrm{OH}$ group ( $\mathrm{C}-7)$ and to the $\mathrm{N}$ atom of the lactam. In addition, the $\mathrm{O}$ atom of the lactam function was exchanged with a C atom ( Fig. 4). Unfortunately, most of these modifications led to a weaker antiproliferative activity. Also the $S$-configuration at C-2 ( Fig. 4) was shown to be of importance for the actions of the alkaloid [46]. Only narciclasine glucosylated at the phenolic group at C-7 ( $\bullet$ Fig. 4) exhibited an in vivo activity comparable to that of the parent compound, but showed a slightly increased bioavailability. Taken together, the medicinal 
chemistry approach to optimize the biological activity of narciclasine did not generate a largely improved compound.

Nevertheless, an important physicochemical property of narciclasine, its poor water solubility, could be improved: The group of G. Pettit converted narciclasine into the water soluble $(4 \mathrm{mg} /$ $\mathrm{mL}$ ) prodrug narcistatin ( $\odot$ Fig. 4 ), a cyclic phosphate bridging the two hydroxyl groups at C-3 and C-4. Narcistatin, which is readily hydrolyzed to narciclasine by unspecific esterases, showed the same pharmacological potency as the parent compound [66].

The group of R. Kiss also evaluated both the pharmacokinetic properties and the adverse effects of narciclasine. In mice, the oral administration of $10 \mathrm{mg} / \mathrm{kg}$ resulted in a peak concentration of $300 \mathrm{ng} / \mathrm{mL}$. The oral bioavailability was calculated as $32 \%$, the terminal elimination half-life after iv application was $66 \mathrm{~min}$ [46]. Of note, the alkaloid was suggested to be able to cross the blood brain barrier, since brain tumors in mice were successfully treated $[48,49]$. Using liver microsomes from different species (rat, mouse, dog, human), narciclasine was found to be metabolically quite stable: After $45 \mathrm{~min}$, only the rodent species evoked a slight decline in the concentration of narciclasine of less than $20 \%$ [46]. However, the observed actions in the brain are not necessarily caused by the compound itself. Its physicochemical properties are not favorable for the permeation of the blood brain barrier. Thus, unknown metabolites of narciclasine could be responsible for these actions. Unfortunately, this interesting issue has not been investigated so far. McNulty et al. [67] reported an inhibitory activity of the alkaloid against the human cytochrome P450 isoenzyme CYP3A4, which points towards an unfavorable interaction profile with a great number of drugs that serve as a substrates of this enzyme.

The side effects of narciclasine were studied in rats: The compound was administered by oral gavage for five consecutive days (Monday to Friday) for 3 weeks at doses of $0,1,3,10$, and $25 \mathrm{mg} /$ $\mathrm{kg} /$ day. The no observed adverse effect level (NOAEL) was $1 \mathrm{mg} /$ $\mathrm{kg} /$ day. Higher doses ( 3 and $10 \mathrm{mg} / \mathrm{kg} /$ day) caused piloerection, diarrhea, lethargy, stomach abnormalities and alterations in red and white blood cell parameters. The highest dose was too toxic and caused death in most of the animals within three days [46].

\section{Summary}

$\nabla$

Taken together, narciclasine shows strong cytotoxic activity (nanomolar range) against a variety of tumor cells in vitro. The in vivo efficacy was very good in brain tumor models, whereas the action was not very pronounced in other types of cancer. Two direct targets of narciclasine have been discovered so far: ribosomes and eEF1A. Recent findings suggest that the actin cytoskeleton and thus processes like cytokinesis and cell migration are disturbed by narciclasine. This new knowledge has challenged the long standing concept of narciclasine primarily acting as an inhibitor of protein biosynthesis. Beyond cancer, a second promising field are inflammatory diseases, since the alkaloid has emerged to exhibit profound antiphlogistic properties in vitro and in vivo. Unfortunately, in particular in the area of inflammation, but also in the much better investigated field of cancer, only few studies provided in-depth insights into altered cellular functions and the underlying molecular mechanism. Moreover, the development of narciclasine is hampered by a lack of efficient supply, since total syntheses are complex and biotechnological approaches are completely missing. Thus, despite all the intrigu- ing findings about narciclasine, it still remains inconclusive whether narciclasine could be advanced to clinical trials.

\section{Conflict of Interest}

$\nabla$

The author declares no conflict of interest.

\section{References}

1 Riddle JM. Ancient and medieval chemotherapy for cancer. Isis 1985; 76: 319-330

2 Gerrard AW. The proximate principles of the Narcissus pseudonarcissus. Pharm J 1877; 8: 214-215

3 Nakagawa $Y$, Uyeo S, Yayima $H$. The double bond in lycorine. Chem Ind 1956; 42: 1238-1239

4 Christenhusz MJM, Byng JW. The number of known plants species in the world and its annual increase. Phytotaxa 2016; 261: 201-217

5 Takos AM, Rook F. Towards a molecular understanding of the biosynthesis of amaryllidaceae alkaloids in support of their expanding medical use. Int J Mol Sci 2013; 14: 11713-11741

6 Ghosal S, Saini K, Razdan S. Crinium alkaloids: their chemistry and biology. Phytochem 1985; 24: 2141-2156

7 Evidente A, Kornienko A. Anticancer evaluation of structurally diverse Amaryllidaceae alkaloids and their synthetic derivatives. Phytochem Rev 2009; 8: 449-459

8 Kornienko A, Evidente A. Chemistry, biology, and medicinal potential of narciclasine and its congeners. Chem Rev 2008; 108: 1982-2014

9 Jin Z. Amaryllidaceae and Sceletium alkaloids. Nat Prod Rep 2013; 30 : 849-868

10 Unver N. New skeletons and new concepts in Amaryllidaceae alkaloids. Phytochem Rev 2007; 6: 125-135

$11 \mathrm{He} \mathrm{M,} \mathrm{Qu} \mathrm{C,} \mathrm{Gao} \mathrm{O,} \mathrm{Hu} \mathrm{X,} \mathrm{Hong} \mathrm{X.} \mathrm{Biological} \mathrm{and} \mathrm{pharmacological} \mathrm{activ-}$ ities of Amaryllidaceae alkaloids. RSC Adv 2015; 5: 16562-16574

12 Ceriotti G. Narciclasine: an antimitotic substance from Narcissus bulbs. Nature 1967; 213: 595-596

13 Piozzi F, Fuganti C, Mondelli R, Ceriotti G. Narciclasine and narciprimine. Tetrahedron 1968; 24: 1119-1131

14 Savona G, Piozzi F, Marino ML. Structure and synthesis of permethylnarciprimine. J Chem Soc Chem Commun 1970; 16: 1006

15 Mondon A, Krohn K. Struktur und Synthese des Narciprimins. Tetrahedron Lett 1970; 11: 2123-2126

16 Immirizi A, Fuganti C. The crystal and molecular structure of narciclasine tetra-acetate. J Chem Soc Chem Commun 1972; 4: 240

17 Okamoto T, Torii Y, Isogai Y. Lycoricidinol and lycoricidine, new plantgrowth regulators in the bulbs of Lycoris radiata. Chem Pharm Bull 1968; 16: 1860-1864

18 Mondon A, Krohn K. Synthesis of narciprimine and related compounds. Chem Ber 1972; 105: 3726-3747

19 Ingrassia L, Lefranc F, Mathieu V, Darro F, Kiss R. Amaryllidaceae isocarbostyril alkaloids and their derivatives as promising antitumor agents. Transl Oncol 2008; 1: 1-13

20 Ghosal S, Lochan R, Ashutosh Kumar Y, Srivastava RS. Alkaloids of Haemanthus kalbreyeri. Phytochemistry 1985; 24: 1825-1828

21 Ghosal S, Singh SK, Srivastava RS. Alkaloids of Zephyranthes flava. Phytochemistry 1986; 25: 1975-1978

22 Abou-Donia AH, De Giulio A, Evidente A, Gaber M, Habib AA, Lanzetta R, Seif El Din AA. Narciclasine-4-O-beta-D-glucopyranoside, a glucosyloxy amidic phenanthridone derivative from Pancratium maritimum. Phytochemistry 1991; 30: 3445-3448

23 Pettit GR, Cragg GM, Singh SB, Duke JA, Doubek DL. Antineoplastic agents: 162. Zephyranthes candida. J Nat Prod 1990; 53: 176-178

24 Pettit GR, Meng Y, Herald DL, Knight JC, Day JF. Antineoplastic agents. 553. The Texas grasshopper Brachystola magna. J Nat Prod 2005; 68: $1256-1258$

25 Rigby JH, Mateo ME. Total synthesis of (+)-narciclasine. J Am Chem Soc 1997; 119: 12655-12656

26 Ghavre M, Froese J, Pour M, Hudlicky T. Synthesis of Amaryllidaceae constituents and unnatural derivatives. Angew Chem Int Edit 2016; 55: 5642-5691

27 Maji B, Yamamoto H. Catalytic enantioselective nitroso Diels-Alder reaction. J Am Chem Soc 2015; 137: 15957-15963

28 Kilgore MB, Kutchan TM. The Amaryllidaceae alkaloids: biosynthesis and methods for enzyme discovery. Phytochem Rev 2016; 15: 317-337 
29 Fuganti C, Mazza M. Late intermediates in the biosynthesis of narciclasine. J Chem Soc Chem Commun 1971; 21: 1388-1389

30 Fuganti C, Staunton J, Battersby AR. The biosynthesis of narciclasine. J Chem Soc Chem Commun 1971; 19: 1154-1155

31 Fuganti C. Evidence for intermediacy of 11-hydroxyvittatine in biosynthesis of narciclasine. Gazz Chim Ital 1973; 103: 1255-1264

32 Fuganti C, Mazza M. The absolute configuration of narciclasine: a biosynthetic approach. J Chem Soc Chem Commun 1972; 4: 239

33 Diamond A, Desgagne-Penix I. Metabolic engineering for the production of plant isoquinoline alkaloids. Plant Biotechnol J 2016; 14: 1319-1328

34 Carrasco L, Fresno M, Vazquez D. Narciclasine: an antitumour alkaloid which blocks peptide bond formation by eukaryotic ribosomes. FEBS Lett 1975; 52: 236-239

35 Jimenez A, Sanchez L, Vazquez D. Yeast ribosomal sensitivity and resistance to the Amaryllidaceae alkaloids. FEBS Lett 1975; 60: 66-70

36 Jimenez A, Sanchez L, Vazquez D. Simultaneous ribosomal resistance to trichodermin and anisomycin in Saccharomyces cerevisiae mutants. Biochim Biophys Acta 1975; 383: 427-434

37 Jimenez A, Sanchez L, Vazquez D. Location of resistance to the alkaloid narciclasine in the 60S ribosomal subunit. FEBS Lett 1975; 55: 53-56

38 Baez A, Angoso G, Vazquez D. Labelling of narciclasine by tritium exchange. Biochimie 1977; 59: 751-753

39 Jimenez A, Santos A, Alonso G, Vazquez D. Inhibitors of protein synthesis in eukarytic cells. Comparative effects of some amaryllidaceae alkaloids. Biochim Biophys Acta 1976; 425: 342-348

40 Dall'Acqua F, Rodighiero C. Investigations on the mechanism of action of narciclasine. Farmaco Sci 1977; 32: 67-75

41 Rodriguez-Fonseca C, Amils R, Garrett RA. Fine structure of the peptidyl transferase centre on 23S-like rRNAs deduced from chemical probing of antibiotic-ribosome complexes. J Mol Biol 1995; 247: 224-235

42 Garreau de Loubresse N, Prokhorova I, Holtkamp W, Rodnina MV, Yusupova G, Yusupov M. Structural basis for the inhibition of the eukaryotic ribosome. Nature 2014; 513: 517-522

43 Pettit GR, Pettit GR 3rd, Backhaus RA, Boyd MR, Meerow AW. Antineoplastic agents, 256. Cell growth inhibitory isocarbostyrils from Hymenocallis. J Nat Prod 1993; 56: 1682-1687

44 Van Goietsenoven G, Mathieu V, Lefranc F, Kornienko A, Evidente A, Kiss $R$. Narciclasine as well as other Amaryllidaceae isocarbostyrils are promising GTP-ase targeting agents against brain cancers. Med Res Rev 2013; 33: 439-455

45 Dumont P, Ingrassia L, Rouzeau S, Ribaucour F, Thomas S, Roland I, Darro $F$, Lefranc F, Kiss $R$. The Amaryllidaceae isocarbostyril narciclasine induces apoptosis by activation of the death receptor and/or mitochondrial pathways in cancer cells but not in normal fibroblasts. Neoplasia 2007; 9: 766-776

46 Ingrassia L, Lefranc F, Dewelle J, Pottier L, Mathieu V, Spiegl-Kreinecker S, Sauvage S, El Yazidi M, Dehoux M, Berger W, Van Quaquebeke E, Kiss R. Structure-activity relationship analysis of novel derivatives of narciclasine (an Amaryllidaceae isocarbostyril derivative) as potential anticancer agents. J Med Chem 2009; 52: 1100-1114

47 Jitsuno M, Yokosuka A, Hashimoto K, Amano O, Sakagami H, Mimaki Y. Chemical constituents of Lycoris albiflora and their cytotoxic activities. Nat Prod Commun 2011; 6: 187-192

48 Lefranc F, Sauvage S, Van Goietsenoven G, Megalizzi V, Lamoral-Theys D, Debeir O, Spiegl-Kreinecker S, Berger W, Mathieu V, Decaestecker C, Kiss $R$. Narciclasine, a plant growth modulator, activates Rho and stress fibers in glioblastoma cells. Mol Cancer Ther 2009; 8: 1739-1750

49 Van Goietsenoven G, Hutton J, Becker JP, Lallemand B, Robert F, Lefranc F, Pirker C, Vandenbussche G, Van Antwerpen P, Evidente A, Berger W, Prevost M, Pelletier J, Kiss R, Kinzy TG, Kornienko A, Mathieu V. Targeting of eEF1A with Amaryllidaceae isocarbostyrils as a strategy to combat melanomas. FASEB J 2010; 24: 4575-4584
50 Mateyak MK, Kinzy TG. eEF1A: thinking outside the ribosome. J Biol Chem 2010; 285: 21209-21213

51 Evidente A, Kireev AS, Jenkins AR, Romero AE, Steelant WF, Van Slambrouck S, Kornienko A. Biological evaluation of structurally diverse amaryllidaceae alkaloids and their synthetic derivatives: discovery of novel leads for anticancer drug design. Planta Med 2009; 75: 501-507

52 Mikami M, Kitahara M, Kitano M, Ariki Y, Mimaki Y, Sashida Y, Yamazaki M, Yui S. Suppressive activity of lycoricidinol (narciclasine) against cytotoxicity of neutrophil-derived calprotectin, and its suppressive effect on rat adjuvant arthritis model. Biol Pharm Bull 1999; 22: 674-678

53 Yui S, Mikami M, Mimaki Y, Sashida Y, Yamazaki M. Inhibition effect of Amaryllidaceae alkaloids, lycorine and lycoricidinol on macrophage TNF-alpha production. Yakugaku Zasshi 2001; 121: 167-171

54 Yamazaki Y, Kawano Y. Inhibitory effects of herbal alkaloids on the tumor necrosis factor-alpha and nitric oxide production in lipopolysaccharide-stimulated RAW264 macrophages. Chem Pharm Bull (Tokyo) 2011; 59: 388-391

55 Lubahn C, Schaller JA, Shewmacker E, Wood C, Bellinger DL, Byron D, Melody N, Pettit GR, Lorton D. Preclinical efficacy of sodium narcistatin to reduce inflammation and joint destruction in rats with adjuvantinduced arthritis. Rheumatol Int 2012; 32: 3751-3760

56 Fuchs S, Hsieh LT, Saarberg W, Erdelmeier CA, Wichelhaus TA, Schaefer L, Koch E, Fürst R. Haemanthus coccineus extract and its main bioactive component narciclasine display profound anti-inflammatory activities in vitro and in vivo. J Cell Mol Med 2015; 19: 1021-1032

57 Gabrielsen B, Monath TP, Huggins JW, Kefauver DF, Pettit GR, Groszek G, Hollingshead M, Kirsi JJ, Shannon WM, Schubert EM, DaRe J, Ugarkar B, Ussery MA, Phelan MJ. Antiviral (RNA) activity of selected Amaryllidaceae isoquinoline constituents and synthesis of related substances. J Nat Prod 1992; 55: 1569-1581

58 Onishi Y, Kawano Y, Yamazaki Y. Lycorine, a candidate for the control of period length in mammalian cells. Cell Physiol Biochem 2012; 29: $407-$ 416

59 Kim J, Park Y, Chun YS, Cha JW, Kwon HC, Oh MS, Chung S, Yang HO. Effect of Lycoris chejuensis and its active components on experimental models of Alzheimer's disease. J Agric Food Chem 2015; 63: 6979_ 6988

60 Baez A, Vazquez D. Binding of [3H]narciclasine to eukaryotic ribosomes. A study on a structure-activity relationship. Biochim Biophys Acta 1978; 518: 95-103

61 Mondon A, Krohn K. Chemistry of narciclasine. Chem Ber 1975; 108: 445-463

62 McNulty J, Mao J, Gibe R, Mo R, Wolf S, Pettit GR, Herald DL, Boyd MR. Studies directed towards the refinement of the pancratistatin cytotoxic pharmacophore. Bioorg Med Chem Lett 2001; 11: 169-172

63 McNulty J, Larichev V, Pandey S. A synthesis of 3-deoxydihydrolycoricidine: refinement of a structurally minimum pancratistatin pharmacophore. Bioorg Med Chem Lett 2005; 15: 5315-5318

64 Rinner U, Hillebrenner HL, Adams DR, Hudlicky T, Pettit GR. Synthesis and biological activity of some structural modifications of pancratistatin. Bioorg Med Chem Lett 2004; 14: 2911-2915

65 Pettit GR, Eastham SA, Melody N, Orr B, Herald DL, McGregor J, Knight JC, Doubek DL, Pettit GR 3rd, Garner LC, Bell JA. Isolation and structural modification of 7-deoxynarciclasine and 7-deoxy-trans-dihydronarciclasine. J Nat Prod 2006; 69: 7-13

66 Pettit GR, Melody N, Simpson M, Thompson M, Herald DL, Knight JC. Antineoplastic agents 500. Narcistatin. J Nat Prod 2003; 66: 92-96

67 McNulty J, Nair JJ, Singh M, Crankshaw DJ, Holloway AC, Bastida J. Selective cytochrome P450 3A4 inhibitory activity of Amaryllidaceae alkaloids. Bioorg Med Chem Lett 2009; 19: 3233-3237 